\title{
UNIVERSIDADE: AUTONOMIA, DIVERSIDADE E INCLUSÃO
}

\author{
UNIVERSIDAD: AUTONOMÍA, DIVERSIDAD E INCLUSIÓN
}

UNIVERSITY: AUTONOMY, DIVERSITY AND INCLUSION

Luiz ANDRADE ${ }^{1}$

RESUMO: O principal objetivo deste ensaio é articular três temas inerentes à universidade: autonomia, diversidade e inclusão. A universidade, enquanto instituição autônoma, mas não soberana, possui propriedades emergentes advindas dos nós conversacionais entre os membros que a integram. Tendo em vista que estas redes de conversações são multidimensionais, diversas e inclusivas, a universidade, entendida como processualidade instituinte e não como realidade instituída, pode sempre gerar novas abordagens, novas formações profissionais, novas intervenções inter e transdisciplinares e, sobretudo, novos sujeitos históricos. É essa especificidade da eficiência universitária que justifica todo nosso esforço em preservar isso que se apresenta como a sua condição de sobrevivência e potencialidade: sua autonomia.

PALAVRAS-CHAVE: Universidade. Autonomia. Diversidade. Inclusão.

RESUMEN: El objetivo principal de este ensayo es articular tres temas inherentes a esta institución secular: autonomía, diversidad e inclusión. La universidad, como institución autónoma, tiene propiedades emergentes de los nodos conversacionales entre sus miembros. Dado que estas redes de conversaciones son multidimensionales, diversas e inclusivas, la universidad, entendida como procesalidad y pero no en una realidad establecida, siempre puede generar nuevos enfoques, nuevos antecedentes profesionales, nuevas intervenciones inter y transdisciplinarias y, sobre todo, nuevos agentes historicos. Es esta especificidad de la eficiencia universitaria lo que justifica todos nuestros esfuerzos para preservar esto que se presenta como su condición de supervivencia y potencialidad: su autonomía.

PALABRAS CLAVE: Universidad. Autonomía Diversidad. Inclusión.

ABSTRACT: Our main objective in that ensay is to articulate three caracteristics issues of that secular institution: autonomy, diversity and inclusion. The university, undertood as an autonomous institution, but not sovereign, produce emergent properties that came from the networks of conversations between its members. Given that these conversational networks are multidimensional, diverse and inclusive, the university, understood as processuality and not as established reality, can always generate new approaches, new professional fields, new inter and transdisciplinary interventions and, above all, new historical subjects. This is the specificity of university efficiency that justifies all our efforts to preserve what is presented as a condition of survival and potentiality: autonomy.

${ }^{1}$ Universidade Federal Fluminense (UFF), Niterói - RJ - Brasil. Professor Associado IV. Departamento de Imunobiologia. ORCID: https://orcid.org/0000-0003-3925-2953. E-mail: labauff@yahoo.com.br

RIAEE - Revista Ibero-Americana de Estudos em Educação, Araraquara, v. 15, n. esp. 2, p. 1600-1614, ago. 2020. e-ISSN: $1982-5587$. DOI: https://doi.org/10.21723/riaee.v15iesp2.13830 
KEYWORDS: University. Autonomy. Diversity. Inclusion.

\section{Introdução}

A história da instituição universitária foi contínua a partir da Idade Média, considerando como marcos referenciais de seu surgimento as Universidades de Bolonha (1190), Oxford (1214) e Paris (1215). Embora as datas que acompanham os nomes dessas Instituições façam referências, muitas vezes, à aprovação dos seus respectivos estatutos, o simples anúncio dos mesmos obscurece o principal legado histórico comum a todas elas - o longo processo de conflitos que marcou a busca, a conquista e a manutenção de suas respectivas autonomias (RENAUT, 1995).

Etimologicamente, autonomia significa lei própria (do grego $\alpha \mu \pi \mathrm{o}=$ próprio; $\eta \circ \mu 1 \alpha=$ lei). O seu antônimo, heteronomia, significa lei externa ou comando, isto é, condição de pessoa ou de grupo que receba de um elemento que lhe é exterior a lei a que se deve obedecer. No âmbito dos sistemas e das instituições, os conceitos de autonomia e heteronomia definem tipos diferentes de organização. O primeiro define sistemas auto-referenciais, de afirmação de si, isto é, sistemas que se determinam a partir da sua própria dinâmica de funcionamento. $\mathrm{O}$ segundo define sistemas cuja identidade é afirmada pelo outro, portanto, sistemas de definição a partir do exterior (VARELA, 1989).

Já tivemos a oportunidade de apresentar, de forma mais ampla e aprofundada, o arcabouço teórico (MATURANA, 1997; 2001) com o qual definimos a universidade e o seu devir histórico com a sociedade (ANDRADE et al., 2000; 2002a). Assim, de forma sucinta, propusemos que a universidade se define como uma rede de conversações acadêmicocientíficas (ANDRADE et al., 2000) e que, com este modus operandi, a universidade produz fenômenos tais quais: a produção da autonomia como fronteira ontológica (ANDRADE et al., 2000, 2002a), uma relação solidária, de afirmação de identidade na construção da alteridade, na ação extensionista (ANDRADE; SILVA, 2001), a dialética do mesmo e do outro na sua coderiva histórica com a sociedade (ANDRADE et al., 2002a) e uma incessante produção criativa, denominada em seu conjunto de poiesis (do grego, criação) universitária (ANDRADE et al., 2002b).

A partir de nosso modelo explicitado acima, entendemos a relação entre a universidade e a sociedade como uma dialética entre dois domínios que se distinguem, mas que não se separam. Assim, ao mesmo tempo em que a universidade se constitui como 
mesmo da sociedade, na medida em que é financiada por ela e é parte inclusa do seu operar, por outro lado, ela é também o outro da sociedade, na medida em que sua força instituinte, seu princípio fundador, é a autonomia. Dessa maneira, é possível deduzir que é na tensão dialética entre o mesmo e o outro que a universidade institui o novo e o transformador na sociedade. Universidades que negam o mesmo da sua realidade instituinte podem ser negadas em seu próprio devir. Do mesmo modo, universidades que abdicam do seu papel de outro, na afirmação de sua autonomia, desaparecem na homogeneização total em relação a um meio que não mais a reconhece como sistema autônomo. A universidade capaz de sustentar a dialética do mesmo e do outro é a universidade necessária ao seu tempo e à sociedade e pode, assim, contribuir de forma original para o parto de um novo mundo.

Há de se fazer uma distinção importante: embora os membros da universidade sejam sujeitos políticos, a universidade, enquanto instituição, não é um partido político. Ela se nutre do dissenso, fundamental ao seu operar, e valoriza o melhor argumento (FIORE, 1995).

A partir do referencial teórico explicitado acima, tendo a autonomia como condição sine qua non para a definição e modus operandi da universidade, passaremos a problematizar os outros dois conceitos que constam no título deste ensaio, quais sejam, diversidade e inclusão.

\section{Diversidade}

Ainda que o conceito de diversidade possa ser utilizado como uma distinção quantitativa, quando se compara dois conjuntos de entidades muito semelhantes, ou como uma distinção qualitativa, quando se compara conjuntos de entidades diferentes que não podem ser substituídas entre si (ABBAGNANO, 2007), estas duas acepções nos ajudam a pensar a diversidade inerente à universidade ou ao sistema universitário como um todo.

Assim, tomando como exemplo uma universidade do porte da Universidade Federal Fluminense (UFF), contabilizamos, como estimativa, cerca de 4.000 docentes, responsáveis por, pelo menos, 3.000 disciplinas, cerca de 50.000 estudantes, distribuídos em uma grande diversidade de áreas do conhecimento e de cursos de graduação e pós-graduação, e cerca 4.000 servidores técnico administrativos. Esta diversidade numérica é, então, ampliada com a pluralidade oriunda das histórias de vida de seus membros, considerando gêneros, vínculos étnicos, classe social, idade, locais de nascimento, instituições de aquisição de formação acadêmica, crenças, concepções de mundo, participação política. Amplia-se ainda mais quando se leva em conta o princípio da liberdade acadêmica. Surgem, assim, distintos 
métodos, técnicas, estilos, concepções, valores, interesses, experiências, vivências, tudo afetando o modo de pensar, de ensinar e de imaginar a própria universidade e o que dela emerge - criatividade (MOTA-SANTOS, 1999).

Um dos maiores estudiosos da criatividade e de grupos criativos, históricos e atuais Domenico de Masi (2002a; 2002b) - ressaltou algumas características de grupos criativos e de seus respectivos ambientes propícios à produção coletiva de criatividade, a saber: equilíbrio entre sonho e concretude, ambiente físico funcional e acolhedor, liberdade de pensamento, respeito aos pontos de vista divergentes, flexibilidade de horários mas, também, sincronismo, pontualidade e permanência ininterrupta até a finalização da tarefa, interdisciplinaridade, complementaridade, disponibilidade de meios culturais e materiais, estímulos e recompensas materiais e simbólicas, e uma liderança capaz de criar um clima psicossocial favorável, orientado tanto para a missão, quanto para o grupo (MASI, 2002a). O autor demonstrou que a dinâmica interpessoal destes grupos não responde a uma lógica linear e hierárquica mas, sobretudo, a uma lógica recursiva na qual cada membro reage a uma complexa rede de interações condutuais, comunicativas e colaborativas (MASI, 2002b). Muitas das características destacadas por Masi (2002a; 2002b) estão presentes nas universidades e, portanto, não é por acaso que, no Brasil, mais de $90 \%$ das pesquisas são realizadas nas universidades públicas.

No que concerne à formação de quadros qualificados para o país, as universidades públicas brasileiras também se destacam. Haja vistas que as redes de conversações acadêmico-científicas presentes nas universidades são multidimensionais e não estão enclausuradas em disciplinas, o potencial de diversidade aumenta extraordinariamente, podendo sempre gerar novas abordagens, novas formações profissionais, novas intervenções inter e transdisciplinares e, sobretudo, novos sujeitos históricos, muitos dos quais oriundos de sua juventude discente - fonte inesgotável de diversidade posto que ela se renova a cada ano.

No Brasil, a diversidade aportada pela juventude estudantil foi incrementada, nestas últimas duas décadas pelo sistema de cotas, mobilidade estudantil e a internacionalização. Diversidade em termos de regionalismos, diferentes classes sociais, imigrações, migrações e contatos interétnicos. Soma-se a isto a experiência vivenciada por mestres e estudantes nos programas de extensão universitária (ANDRADE; SILVA, 2001) e extensão reversa (SANTOS, 2019; TAKAHASHI, 2015), duas formas de interagir com a sociedade e incorporar novidades.

Ainda que alguns autores tenham compreendido o aumento da diversidade e da complexidade das universidades modernas como "multiversidade" (KERR, 2001) ou 
pluriversidade (SANTOS, 2019), acreditamos que renomear não seja a melhor formulação para se compreender as mudanças estruturais ocorridas no âmbito desta instituição quase milenar e, assim, contribuir para seu aprimoramento. Há de se ressaltar, no contexto histórico no qual a denominação de multiversidade foi proposta (KERR, 2001), ou seja, nos Estados Unidos, que a universidade americana cresceu como uma combinação de vários modelos precedentes, incorporando, do modelo medieval, a formação profissional, do modelo de Newman (1996), a educação liberal, do modelo alemão, a pesquisa, do modelo escocês, a ciência aplicada, e ainda os elementos distintivos e característicos da sociedade americana, incluindo o forte investimento do Estado na pesquisa e no ensino de pós-graduação, justificado pela importância que a ciência teve para a vitória daquele país e de seus aliados, na segunda guerra mundial (FALLIS, 2007). Foi esta estrutura diversa e conglomerada que o referido autor denominou de multiversidade, para assinalar a existência de vários interesses internos díspares e conflituosos dentro da mesma instituição (KERR, 2001). O autor assinalou ainda o importante papel desempenhado por esta instituição na produção de conhecimento e no desenvolvimento econômico dos Estados Unidos. Corroboramos com o referido autor sobre a importância da universidade para o crescimento econômico, inovação industrial e competitividade internacional, sobressaindo aos valores tradicionais como recursos naturais, manufatura e chão de fábrica (DILL; VUGHT, 2010), mas não corroboramos com a necessidade de renomear a universidade para "multiversidade". Afirmamos isto a partir de nossa compreensão que a universidade se constituiu, desde os seus primórdios, com uma diversidade intrínseca, criativa e que sempre soube se fazer, e se manter, por meio de mudanças estruturais, como uma necessidade histórica da sociedade e não uma simples contingência histórica (ANDRADE, 2002a). Assim, para o seu aprimoramento, melhor que renomear a instituição, seria compreender e garantir o financiamento e a autonomia institucional em face das forças heteronômicas de sua circunstância, especialmente o mercado.

Na percepção de Santos (2019), de crítica à ordem estabelecida, a universidade deveria ser ainda mais diversa quanto aos seus ingressantes - culturas e classes sociais excluídas - e quanto aos métodos e epistemologias, ou seja, ela deveria ser descolonizada com relação à epistemologia europeia. Para dar conta deste movimento em prol do aumento da diversidade o referido autor sugere o nome pluriversidade, e para adjetivar a luta institucional emancipatória em prol daqueles que foram historicamente excluídos, ou que não se enquadram no modelo cultural eurocêntrico, ele clama por uma "subversidade". Nos dois sentidos, diversidade e emancipação, espera-se que a busca incessante pela igualdade entre as diferentes culturas 
(multiculturalismo emancipatório) proporcione uma redistribuição social do ponto de vista econômico e, também, o resgate epistêmico de valores e modos de viver e pensar o mundo a partir de culturas do sul que, historicamente, vem sofrendo um verdadeiro epistemicídio (SANTOS, 1999; 2019).

Embora nossos compromissos éticos e políticos se pautem, no campo social, por uma sociedade mais justa e igualitária e, no âmbito interno da universidade, pela criação de novos paradigmas científicos, ressignificação de visões e de práticas e convivência com diferentes epistemologias advindas de um multiculturalismo emancipatório (ANDRADE; SILVA, 2005), não corroboramos com a ideia de renomear a instituição, haja vista que, de acordo com o nosso modelo, as mudanças estruturais da universidade podem acontecer na sua coderiva histórica com a sociedade, como uma ressignificação a partir de suas lutas internas, na dialética do mesmo e do outro, entendendo este outro como resultado de sínteses produzidas pelas contradições sociais de cada época. Para o modelo da coderiva histórica, da dialética do mesmo e do outro, não existe uma universidade socialista no âmbito de uma sociedade capitalista e vice-versa (ANDRADE et al., 2002). No entanto, a universidade pode mudar sua estrutura como resultado de grandes mudanças sociais ou como resultado de suas lutas internas. Uma destas lutas travadas no campo social - inclusão social - e no âmbito educacional - educação inclusiva - vem sendo discutida nas Conferências Nacionais de Educação e nos Planos Nacionais de Educação e já dispõem de metas, estratégias e dispositivos legais norteadores, para os quais todo o sistema educacional, incluindo as universidades, tentam se aprimorar para dar o melhor cumprimento legal e ético.

\section{Inclusão}

Enquanto o conceito de diversidade faz referência à variedade, à diferença, usando, para tanto, critérios de distinções e argumentos racionais, o conceito de inclusão traz à baila condutas de aceitação da legitimidade do outro na convivência e, portanto, os referenciais são mais emocionais do que racionais, marcados por condutas éticas. Se isto for aceito, gostaríamos de afirmar a impossibilidade de abordar a inclusão social, seja ela em qual nível for, universitária, no nosso caso, sem levar em conta princípios éticos de conduta. Ainda que muitos autores considerem a ética como estudo ou ciência dos juízos de apreciação referente à conduta humana susceptível de qualificação do ponto de vista do bem e do mal, Maturana (1997), nos propõe outro caminho explicativo ao afirmar que as emoções são mais importantes 
do que as racionalizações para se compreender a ética. Ainda que o argumento do autor seja simples e singelo, ele é contundente. Assim diz ele:

A ética tem a ver com a preocupação que uma pessoa tem sobre as consequências negativas de seu atuar sobre outros seres humanos. Se o outro tem presença para uma pessoa e esta pessoa se preocupa com o que se passa com o outro, em decorrência de um ato efetivo ou potencial, esta preocupação está no âmbito da ética (MATURANA, 1997).

Se a ética for assim entendida, ela não deve ser confundida com investigação ou apreciação, seja ela filosófica ou científica, posto que o seu referencial não é externo àquele ou àquela que se preocupa com o outro. É certo que podemos racionalizar e sistematizar as condutas para discriminar o bem e o mal, ou para compreender o comportamento de uma sociedade em um determinado tempo e lugar, mas o principal referencial da ética é o próprio ser humano, ou seja, sua abertura emocional para a legitimidade da presença do outro, na diferença (MATURANA, 1997).

Há de se ressaltar, no entanto, que nem sempre a aceitação de uns para com os outros ocorre assim, pacificamente, sem a manifestação de conflitos, conclamando, portanto, mediações assentadas nas regras de convivialidade, na jurisprudência pátria, na Carta Magna e no estado democrático de direito. Considerando que o texto constitucional brasileiro é o resultado de diferentes cosmovisões e disputas ideológicas e políticas, havemos de valorizar o adjetivo "Cidadã" de nossa Carta Magna de 1988, pela sua clara demonstração de preocupações éticas no que concerne à educação, formação integral, qualificação para o trabalho e exercício pleno da cidadania, para todos.

É com este entendimento e compromisso ético-político que trazemos à baila a discussão sobre inclusão, no âmbito universitário. Neste contexto, as perguntas que se colocam são: quais grupos sociais se encontram excluídos da universidade e qual é a melhor forma de incluí-los. A resposta à primeira pergunta é relativamente fácil de ser respondida e já foi tema de vários estudos (SCHWARTZMAN, 2006; DINIZ; RANGEL, 2018).

Assim, no Brasil, os estudos destacam todos aqueles que se encontram em condições de vulnerabilidade social ou que foram historicamente excluídos - afrodescendentes, indígenas e pessoas com deficiências. $\mathrm{O}$ gênero feminino saiu deste grupo e já é maioria nas universidades brasileiras, no entanto, as mulheres ainda sofrem de um viés implícito que as inferiorizam em disputas por cargos eletivos, cargos de poder e financiamento de grupos de pesquisa (GREENWALD; KRIEGER, 2006; STAATS et al., 2015). O "viés implícito" 
refere-se a uma variedade de preconceitos automáticos e inconscientes em que um grupo é favorecido, no caso os homens, em relação a outro grupo - as mulheres.

A segunda pergunta, no entanto, não tem uma resposta única e objetiva, pois faz parte de um longo processo sociopolítico - luta e conquista de direitos, criação de novos direitos e busca incessante por uma sociedade mais justa e igualitária - e também da política acadêmica e administrativa da universitária - adequação física, estabelecimento de estratégias pedagógicas, uso de tecnologias assistivas, formação de recursos humanos e busca de uma infraestrutura que garanta o acolhimento de todos, com acessibilidade universal (GALVÃO; DAMASCENO, 2002; MANZINI; DELIBERATO, 2007; DINIZ; RANGEL, 2018).

Ainda que não seja nosso objetivo neste ensaio abordar a segunda questão de forma exaustiva, gostaríamos de externar alguns comentários mais gerais que podem servir como balizamento para outros estudos e debates.

\section{Vulnerabilidade social e programas de apoio}

As estatísticas de desempenho dos estudantes nas provas para ingresso nas universidades públicas brasileiras - ENEM - quando sobrepostas com o perfil socioeconômico dos candidatos, mostram que as maiores diferenças nas performances dos estudantes na resolução das provas se devem à renda familiar, à educação dos pais, e outras variáveis tais como o tipo de escola que o jovem frequentou (SCHWARTZMAN, 2006). Se considerarmos que a educação dos pais e o tipo de escola frequentada pelo jovem pode, também, ter a renda familiar como fator determinante, assim como a herança cultural muitas vezes também é dependente da renda familiar, poderíamos afirmar que a exclusão histórica de uma grande parte da população na esfera social e na universidade se deve, majoritariamente, a má distribuição de renda no Brasil. Neste sentido, enquanto isto não for estruturalmente mudado, a única solução, compensatória, passa por políticas públicas colocadas em prática pelos governos e pelos programas de apoio e de assistência estudantil promovidos pelas universidades. Nestes programas se incluem: alimentação subsidiada, moradia estudantil, bolsas de trabalho, bolsas de desenvolvimento acadêmico, monitoria, iniciação científica, extensão universitária e outras. Acreditamos que o esforço individual do estudante, associado aos programas de assistência estudantil, incluindo a oferta de bolsas, sejam mais importantes para o bom desempenho do ingressante oriundo das classes populares do que os próprios cursos de nivelamento ofertados pela Universidade. 


\section{Afrodescendentes e o Sistema de Cotas}

Quando nos perguntam em formulários, questionários ou censos demográficos sobre o nosso enquadramento enquanto raça, respondemos com firmeza e indignação -humana. Enquanto biólogos devemos insistir que não existem raças humanas e melhor seria se as pessoas fossem tratadas como iguais, na diferença. Mesmo os gêmeos univitelinos, a depender da epigênese e das histórias de vida, são diferentes. A cor da pele está, literalmente, à flor da pele (PENA, 2007). As feições de rosto, tipo de cabelo e, especialmente, a cor da pele, depende, apenas, de pouco mais de uma dezena de genes, em um total de cerca de 25 mil, que constitui o genoma humano (PENA, 2007). Para além disto, vários estudos demonstram que existe mais diferenças genéticas dentro de uma mesma população humana, considerando um país ou um continente, do que entre populações de outros continentes e, portanto, o conceito de raça humana, para a biologia, está totalmente superado. Da mesma forma, não existem determinantes genéticos para inteligência ou capacidade cognitiva dos diferentes agrupamentos humanos. As maiores diferenças encontrados entre os humanos, no que concerne ao que denominamos capacidade cognitiva, são culturais, ou seja, depende das condições ambientais (alimentação e estímulos) e de outros fatores, especialmente a educação. Isto fica evidente ao compararmos indivíduos de diferentes agrupamentos humanos ou etnias que, quando criados em ambientes culturalmente ricos, não apresentam diferenças marcantes em suas capacidades cognitivas, quando comparados aos indivíduos da sociedade que os acolheram.

Ao afirmarmos que não existem raças humanas e que todos os seres humanos são, de uma forma ou de outra, cognitivamente capazes, não quer dizer que estejamos afirmando que não exista o fenômeno historicamente excludente, sociologicamente nefasto, que é o racismo. Assim, não somos contrários às políticas públicas compensatórias como as cotas e os programas de inclusão social e de apoio aos estudantes no âmbito universitário. Sabemos, no entanto, que estas políticas públicas e as referidas cotas não vão durar para sempre, especialmente quando se igualarem as oportunidades e a cor deixar de ser um marcador de pobreza. Enquanto isto não acontecer, os grupos excluídos, sejam eles afrodescendentes, imigrantes, indígenas, e mesmo aqueles marcados por diferenças de gênero ou de preferencia sexual, deverão receber o mesmo apoio diferencial da sociedade e da universidade para que a igualdade de oportunidades seja minimamente garantida. Isto foi brilhantemente explicitado por Boaventura Santos (2003) quando ele afirmou que: 
Temos o direito de ser iguais quando a nossa diferença nos inferioriza; e temos o direito de ser diferentes quando a nossa igualdade nos descaracteriza. Daí a necessidade de uma igualdade que reconheça as diferenças e de uma diferença que não produza, alimente ou reproduza as desigualdades (SANTOS, 2003, p. 56).

\section{Pessoas com deficiências, acessibilidade e Tecnologias Assistivas}

A entrada mais expressiva de pessoas com deficiências tornou-se um desafio relativamente novo para a universidade. Ainda que a universidade tenha, outrora, recebido pessoas com vários tipos de deficiências em seus cursos e em seus quadros, estes eventos eram raros. A entrada de um contingente mais expressivo ocorreu a partir de vários movimentos sociais unidos pela pauta da inclusão e de uma conjuntura internacional e nacional mais sensível a esta grande causa. Não menos importante, se destaca também a aprovação da educação inclusiva na Lei de Diretrizes e Bases da Educação Brasileira e, por extensão, no seio da universidade. Esta nova realidade fez com que a universidade buscasse se adaptar, repensando alguns de seus paradigmas, mas, sobretudo, desenvolvendo novas estratégias pedagógicas. $\mathrm{Na}$ esteira destes movimentos, a universidade vem tentando também mudar sua própria infraestrutura física, especialmente no que tange à construção de um novo paradigma de acessibilidade universal, com vistas ao melhor acolhimento das pessoas com deficiências. Embora a perspectiva de que as instituições universitárias venham, em curto e médios prazos, melhorar suas situações em termos de acessibilidade e inclusão, um estudo recente mostra que ainda falta muito para se chegar ao ideal de acessibilidade (DINIZ et al., 2019). Há de se ressaltar, neste contexto, que pode ocorrer acessibilidade sem inclusão, mas o inverso é inviável.

Considerando que todos os indivíduos são igualmente sujeitos de direitos e deveres e necessitam de um acolhimento digno para o exercício pleno da cidadania, a universidade vem buscando construir e adequar espaços cognitivos com tecnologias assistivas e pessoal especializado - tradutores e interpretes. Neste sentido, ressalta-se a importância de se observar as normas de acessibilidade e mobilidade segura e autônoma, total ou assistida, às pessoas com deficiências e àqueles que apresentam mobilidade reduzida (DINIZ; RANGEL, 2018). Ainda que as tecnologias assistivas constituem uma ampla variedade de recursos (mecânico, elétrico, eletrônico, computadorizado, etc) destinados a dar suporte às pessoas com deficiência (MANZINI; AUDI, 2006), dois grandes problemas dificultam a realização plena deste objetivo ético na universidade, a saber: (a) pronta aquisição, em quantidade, de produtos derivados de tecnologias assistivas; (b) a contratação de recursos humanos especializados para operar estes produtos e tecnologias nos espaços pedagógicos, com a 
devida mediação do professor (SKLIAR, 1998). As tecnologias assistivas - luvas inteligentes, que convertem os movimentos da língua de sinais em áudio, bengalas sensoriais, DOS-VOX, são bem-vindas, mas elas devem estar atreladas à pedagogia do Outro, e não de outro, como problematizado por Skliar, 2003. Nesta mesma linha de preocupação ética com o Outro, Merleau-Ponty nos convoca à reflexão:

Como nomear, como descrever esta vivência de outrem, tal como a vejo de meu lugar, vivência que, todavia, nada é pra mim, já que creio em outrem - e que, alias, concerne a mim mesmo, já que ai está como visão de outro sobre mim [...]. Por certo, a menor retomada da atenção me convence de que esse outro que me invade é todo feito de minha substância: suas cores, sua dor, seu mundo, precisamente enquanto seus, como conceberia eu senão em que vivo? Pelo menos, meu mundo privado deixou de ser apenas meu; é agora, instrumento manejado pelo outro, dimensão de uma vida generalizada que se enxertou à minha (MERLEAU-PONTY, 2014, p. 21).

Haja vista que em nosso modelo (ANDRADE et al., 2000; 2002) as conversações acadêmico-científicas entre mestres e estudantes são centrais para o modus operandi da universidade, aprofundaremos um pouco mais sobre a inclusão de estudantes surdos, posto que, no Brasil, (a) a surdez ocupa, em termos quantitativos, o $4^{\circ}$ lugar entre o número de deficientes do país, com um quantitativo populacional estimado em cinco milhões de brasileiros; e (b) os surdos se comunicam, prioritariamente, por meio de uma língua própria Língua Brasileira de Sinais (LIBRAS) - e interagem preferencialmente entre si, com fortes vínculos interpessoais, como uma verdadeira comunidade. Haja vista que a LIBRAS possui todos os níveis linguísticos - fonológico, morfológico, sintático, semântico e pragmático encontrados em qualquer língua (BRITO, 1995), e que a grande maioria dos docentes universitários não domina a LIBRAS, torna-se essencial a contratação de intérpretes para auxiliar na "mediação da mediação" entre mestres e estudantes. Esta questão é delicada, posto que a LIBRAS, por ser uma língua mais recente, não possui ainda muitos conceitos acadêmicos e científicos usados, por exemplo, no português ou no inglês. Assim, estes conceitos necessitam ser criados incessantemente, o que requer grupos de pesquisa atuando junto aos docentes e à comunidade surda. Esta questão é ampliada por Mendes e Novaes (2002) quando os referidos autores afirmam que:

[...] muitos leitores surdos têm pouco conhecimento de vocabulário, o qual exige maior elaboração que a simples definição da palavra; dificuldades com a sintaxe do material de leitura, que compromete a compreensão; pouco conhecimento da linguagem figurada, que pode estar relacionado a pouca exposição a expressões idiomáticas e linguagem metafórica (NOVAES; MENDES, 2002, p. 134). 
Como conclusão deste tópico, diríamos que a universidade, enquanto instituição, tem que investir em tecnologias assistivas, mas o maior entrave continua a ser a mediação pedagógica entre o docente universitário e os discentes surdos. Há de se ressaltar que populações indígenas que frequentam os diferentes cursos universitários também estão expostas a este mesmo problema de mediação, ainda que em menor escala e com diferenças intrínsecas, dependendo da região e do domínio do português como segunda língua.

\section{Considerações finais}

Um grande desafio da Universidade pública brasileira, na atualidade, é o da manutenção de sua autonomia frente às forças heteronômicas e à insensatez governamental, que não valoriza a ciência e a tecnologia e, a partir de um projeto ultraliberal, vem retirando direitos socialmente conquistados, implementando cortes no financiamento das universidades públicas, forçando-as a um "future-se" no âmbito de um projeto de privatização da esfera pública. A dificuldade não está em rejeitar este "future-se" imposto, e impostor, mas enfrentar duras carências que, a se perpetuar por mais alguns anos, podem fragilizar o ethos acadêmico e, assim, ameaçar drasticamente o princípio fundador da universidade: sua autonomia.

Assim, é preciso traçar regras claras para a captação de recursos externos, definindo aberturas, estabelecendo trincheiras, reforçando sempre o coletivo institucional em contraposição às saídas individuais ou de pequenos grupos que arrogam, para si, privilégios baseados em certas competências científicas ou tecnológicas de grande interesse para o mercado, fora do controle da instituição e de seu estatuto legal. Para além disso, como um compromisso ético, deveremos nos posicionar e trabalhar em prol da inclusão social e também no âmbito universitário, posto que isto propicia novas dinâmicas que enriquecem a própria Universidade, com a possibilidade de socialização de um conhecimento produzido segundo uma perspectiva não apropriadora ou competitiva. Tendo em vista que as questões éticas são inerentes ao viver humano, destacamos a ética, ou as questões éticas, como um dos temas a serem tratados permanentemente pela universidade. Fazemos este destaque por acreditarmos que o desenvolvimento humano não se restringe ao econômico e/ou tecnológico.

Destarte, advogamos que as questões pedagógicas e o conteúdo programático das disciplinas devam estar conjugados sempre às questões éticas. $\mathrm{O}$ realce à ética e à solidariedade prefigura um certo matiz utópico de nossa análise e de nossas proposições, 
particularmente neste momento histórico de retrocesso de direitos conquistados e do ressurgimento e autorização, pelo próprio governo, da cultura do ódio.

\section{REFERENCIAS}

ABBAGNAMO, N. Dicionário de filosofia. 5. ed. São Paulo: Martins Fontes, 2007.

ANDRADE, L. A. B.; SILVA, E. P. Dialética, diálogo e conversa: consonâncias e dissonâncias epistemológicas entre Freire e Maturana. Revista Educação Brasileira, Distrito Federal, v .27, n. 55, p.51-77, 2005.

ANDRADE, L. A. B.; SILVA, E. P. Universidade e sua relação com o outro: um conceito para extensão universitária. Revista Educação Brasileira, Distrito Federal, v. 23, n. 47, p. 65-79, 2001.

ANDRADE, L. A. B.; SILVA, E. P.; LONGO, W. P.; PASSOS, E. A utopia da poieis universitária. Revista Educação Brasileira, Distrito Federal, v. 24, n. 48-49, p. 61-78, 2002.

ANDRADE, L. A. B.; SILVA, E. P.; LONGO, W. P.; PASSOS, E. Coderiva: uma historia de congruência entre universidade e sociedade. Movimento. Revista da Faculdade de Educação da UFF, Niterói, v. 6, p. 58-89, 2002.

ANDRADE, L. A. B; LONGO, W. P.; PASSOS, E. Autonomia como um modelo explicativo da ontologia da universidade. Revista Universidade e Sociedade, Distrito Federal, n. 21, p. 73-84, 2000.

BRITO, L. F. Por uma gramática de língua de sinais. Rio de Janeiro: Tempo Brasileiro, 1995.

DILL, D.; VUGHT, F. Introduction. In: DILL, D.; VUGH, F. (Eds.). National Innovation and the Academic Research Enterprise. Baltimore, MD: John Hopkins University Press, 2010.

DINIZ, C. N.; ASSIS, J. B.; ALVES, L. D. Perspectivas da acessibilidade e inclusão de pessoa com deficiência nas universidades federais brasileiras da ótica de seus sítios e bibliotecas In: DNA Educação. v. 2. 1. ed. São Paulo: Dialogar, 2018. p. 97-120.

DINIZ, C. N.; RANGEL, A. V. Acessibilidade arquitetônica em biblioteca escolar: algumas recomendações para adaptações. P. 279-293. In: DICKMANN, I. (Org.). Caminhos da Educação - Percorrer juntos novas trilhas pedagógicas e encontrar novos caminhos da educação. v. I. São Paulo: Editora Diálogo Freiriano, 2018.

FALLIS, G. Multiversities, ideas, and democracy. Toronto, ON: University of Toronto Press, 2007.

FIORI, J. L. Em busca do dissenso perdido. Ensaios críticos sobre a festejada crise do estado. Rio de janeiro: Insight, 1995. 
GALVÃO, T. A. F.; DAMASCENO, L. L. Educação especial e novas tecnologias: o aluno construindo sua autonomia. Brasília, DF: PROINFO, MEC, 2002.

GREENWALD, A. G, KRIEGER, L. H. Implicit bias: scientific foundations. Cal. L. Rev., v. 94, n. 4, p. 945-968, 2006. Disponível em: https://lawcat.berkeley.edu/record/1120596.

Acesso em: jul. 2019. DOI: http://dx.doi.org/https://doi.org/10.15779/Z38GH7F

KERR, C. The uses of the university. 50. ed. Cambridge, MA: Harvard University Press, 2001 .

MANZINI, E. J.; DELIBERATO, D. Portal de ajudas técnicas para educação:

equipamento e material pedagógico especial para educação, capacitação e recreação da pessoa com deficiência física: recursos pedagógicos adaptados II. Secretaria de Educação Especial. Brasília: ABPEE - MEC: SEESP, 2007.

MASI, D. D. Criatividade e grupos criativos. Descoberta e invenção. v. 1. Rio de Janeiro: Editora Sextante, 2002a. 464p.

MASI, D. D. Criatividade e grupos criativos. Fantasia e concretude. v. 2. Rio de Janeiro: Editora Sextante, 2002b. 310p.

MATURANA, H. A ontologia da realidade. Editora UFMG, Belo Horizonte, 1997.

MATURANA, H. Cognição, ciência e vida cotidiana. Editora UFMG, Belo Horizonte, 2001.

MERLEAU-PONTY, M. O visível e o invisível. 4. ed. Trad. Artur Gianotti e Armando Mora d'Oliveira. São Paulo: Perspectiva, 2014. 271p.

MOTA-SANTOS, T. A. Discurso proferido na transmissão de cargo de Reitor da UFMG ao Prof. Francisco César de Sá Barreto. UFMG, 1998.

NEWMAN, J. H. The idea of a university. New Haven, CT: Yale University Press, 1996.

PENA, S. D. À flor da pele: reflexões de um geneticista. Rio de Janeiro: Vieira \& Lent, 2007.

RENAUT, A. Les révolutions de l'univeristité: essai sur la modernisation de la culture. Paris: Calmann-Lévy, 1995.

SANTOS, B. S O fim do império cognitivo: a afirmação das epistemologias do sul. Belo Horizonte: Autêntica Editora, 2019.

SANTOS, B. S. A crítica da razão indolente: contra o desperdício da experiência. v. 1. 4. ed. São Paulo, Cortez, 2002.

SANTOS, B. S. Da ideia de universidade à universidade de ideias. In: Pela mão de Alice: o social e o político na pós-modernidade. São Paulo: Cortez, 1999. 
SANTOS, B. S. Reconhecer para libertar: os caminhos do cosmopolitanismo multicultural. Rio de Janeiro: Civilização Brasileira, 2003.

SCHWARTMAN, S. Inclusão Social na Universidade: uma questão pertinente? In: SIMPÓSIO UNIVERSIDADE E INCLUSÃO SOCIAL - EXPERIÊNCIA E IMAGINAÇÃO, 2006, Universidade Federal de Minas Gerais. Anais [...]. Universidade Federal de Minas Gerais 2006. Disponível em:

http://www.schwartzman.org.br/simon/nclusao_ufmg.pdf. Acesso em: jul. 2019.

SKLIAR, C. A Surdez: um olhar sobre as diferenças. Porto Alegre: Mediação, 1998.

SKLIAR, C. A. A educação e a pergunta pelos outros: diferença, alteridade, diversidade e os outros “outros". Ponto de Vista, Florianópolis, n. 5, p. 37-49, 2003.

STAATS, C.; CAPATOSTO, K.; WRIGH, R. A.; CONTRACTOR, D. State of the science: implicit bias review. Kirwan Institute for the study of race and ethnicity, 2015.

TAKAHASHI, R. Proposta de formação transversal: saberes tradicionais. Belo Horizonte: UFMG, 2015. Disponível em: https://www.ufmg.br/online/arquivos/036863.shtml. Acesso em: jul. 2019.

VARELA, F. Autonomie et connaissance. Paris: Seuil, 1989.

\section{Como referenciar este artigo}

ANDRADE, L. Universidade: autonomia, diversidade e inclusão. Revista Ibero-Americana de Estudos em Educação, Araraquara, v. 15, n. esp. 2, p. 1600-1614, ago. 2020. e-ISSN: 1982-5587. DOI: https://doi.org/10.21723/riaee.v15iesp2.13830

Submetido em: 30/08/2019

Revisões requeridas: $30 / 11 / 2019$

Aprovado em: 02/02/2020

Publicado em: 01/08/2020 